\title{
Educação Profissional de Pessoas com Deficiência: adaptações para a acessibilidade
}

\author{
Michelle Pinto Lima*
}

Mônica Carvalho Alves Cappelle*

\section{Resumo}

Este artigo foi realizado com o objetivo de conhecer as adaptaçôes curriculares realizadas no âmbito da Educação Profissional que atende pessoas com deficiência. Para o estudo, foram selecionadas sete instituiçốes educacionais que ofertam esta modalidade de ensino, sendo elas: SENAC, SENAI e Organizaçôes não governamentais (ONGs) de atendimento à pessoa com deficiência. A coleta de dados se deu com o uso de entrevistas semiestruturadas realizadas com representantes destas instituiçôes que estão à frente do planejamento e da organização dos cursos. A natureza qualitativa do estudo permitiu o tratamento dos dados por análise de conteúdo, de forma essencialmente temática. Os resultados obtidos na investigação demonstram que as ONGs se destacam em relaçáo ao sistema $S$ pela diversidade de medidas adaptativas empregadas no atendimento das necessidades educacionais especiais destas pessoas.

Palavras-chave: Educação das pessoas com deficiência. Educação Profissional. Adaptação Curricular.

\footnotetext{
* Mestre em Administração pela Universidade Federal de Lavras (UFLA). Professora da Universidade Federal de Itajubá (UNIFEI).

${ }^{* *}$ Doutora em Administração pela Universidade Federal de Minas Gerais (UFMG). Professora do Departamento de Administração da Universidade Federal de Lavras (UFLA).
} 


\section{Introdução}

O objeto de pesquisa, neste trabalho, é a educação profissional de pessoas com deficiência. Trata-se de problemática relevante para a proposição de políticas públicas que envolvem as pessoas com deficiência e sua inclusão na sociedade por meio do trabalho. Acredita-se que, antes mesmo de pensar na reserva de vagas nas empresas para essas pessoas como medida de proteção e garantia dos seus direitos, é necessário repensar a trajetória de formação que elas têm atualmente disponíveis, no que tange à preparação para o trabalho.

Programas específicos de emprego foram criados no Brasil para esse público, como a Lei no 8.213, de julho de 1991 (BRASIL, 1991), que estabelece cotas para a contratação de pessoas com deficiência, regulamentada pelo Decreto $n^{\circ} 3.298 / 1999$, que obriga as empresas com cem ou mais empregados a preencherem de dois a cinco por cento de seus cargos com beneficiários da Previdência Social reabilitados ou com pessoa portadora de deficiência habilitada, ou seja, que cumpram a "Lei de Cotas" (BRASIL, 1999).

Mas a efetivação dessa inclusão por meio do trabalho tem passado por alguns entraves. Ribeiro e Carneiro (2009) apontam que muitas empresas protelam a contratação de pessoas com deficiência porque estas não preenchem as credenciais necessárias para o desempenho no cargo, não possuindo habilidades técnicas, experiência e qualificação suficientes para as ocupações produtivas. A baixa escolaridade, com predominância do ensino fundamental ou médio, está na lista dos motivos apontados para a dificuldade na contratação destas pessoas.

A dificuldade para a escolarização é apontada por Tanaka e Manzini (2005). Para os autores, muitas pessoas com deficiência enfrentam dificuldades de acesso à escola formal, devido à barreiras arquitetônicas e atitudinais, à falta de recursos didáticos e à inadequação dos métodos de ensino. Como consequência, o nível de formação básica que elas conseguem alcançar na sua trajetória educativa interfere no itinerário de formação para o trabalho que têm conseguido perfazer.

Os dados da educação especial, obtidos por meio do Censo Escolar, levantamento estatístico realizado anualmente pelo Ministério da Educação, apontam que é pouco expressiva a participação de alunos com necessidades educacionais especiais no ensino médio e na educação profissional, com apenas 9\% das matrículas do ano de 2005 e apenas 6,3\% de matrículas na educação 
profissional. Dados deste mesmo ano também apontam que a concentração de matrículas na modalidade de educação profissional no nível básico é muito maior que no nível técnico. São 46.949 pessoas no ensino básico contra 1.962 no ensino técnico. Sem a conclusão do ensino médio, requisito de seleção para o ensino técnico, fica difícil o acesso de pessoas com deficiência à educação profissional em um nível mais elevado.

Infelizmente não é possível comparar os dados acima com os obtidos no Censo Escolar da Educação Básica 2012 (BRASIL, 2013), pois não são computados separadamente a quantidade de alunos com deficiência que há em cada nível de ensino, como feito anteriormente. Mas os dados recentes apontam para um aumento expressivo na quantidade de alunos com necessidades educacionais especiais incluídos em escolas regulares em todos os níveis e modalidades de ensino, com grande concentraçáo no ensino fundamental, 485.965 alunos, 42.499 no ensino médio e apenas 1.659 alunos na Educação Profissional.

Comparando os resultados do Censo Escolar com os do último Censo da população brasileira (IBGE, 2010) é possível confirmar que os esforços para colocar mais pessoas com deficiência na escola estão obtendo êxito. Os dados indicam que $95,2 \%$ das crianças de 6 a 14 anos de idade com deficiência frequentam a escola, confirmando a grande concentração de alunos no ensino fundamental. Em relação ao nível de instrução, $61,1 \%$ da população de 15 anos ou mais com deficiência não tinham instrução ou possuía apenas o fundamental incompleto. Quanto ao ensino superior, apenas 6,7\% tinham ensino superior completo e, das 44 milhóes de pessoas com deficiência em idade ativa (10 anos ou mais), mais da metade $(53,8 \%)$ não estava ocupada.

Ainda que essa aparente democratização do acesso à escola esteja acontecendo e açóes afirmativas sendo desenvolvidas em prol da maior participação de pessoas com deficiência no mundo do trabalho, os resultados dessa política de inclusão só poderão ser mensurados daqui a alguns anos. Por enquanto, as pessoas com deficiência em idade para o trabalho são resultado de um longo período de exclusão educacional. Além da dificuldade de acesso à escola, regular ou especial, os poucos alunos que frequentaram a escola não receberam uma educação apropriada, seja por falta de profissionais qualificados ou mesmo pela falta generalizada de recursos (MENDES, 2006). Daí a dificuldade apontada pelos empregadores de encontrar pessoas com deficiência com um perfil empregatício compatível com as exigências profissionais. 
Como as medidas de apoio ao trabalho não foram suficientes para garantir a empregabilidade deste público, tornou-se necessário também intervir nas políticas educacionais para atendê-los, proporcionando às pessoas com deficiência adultas a oportunidade de ter alguma qualificação para ser um "cidadão produtivo"(FRIGOTTO; CIAVATTA, 2006). Jovens e adultos a quem foi negado o direito à escolaridade básica ou concedida apenas por alguns anos, passaram a procurar instituições educacionais para obter a qualificação exigida para se tornarem sujeitos "empregáveis".

Esses cursos, organizados na modalidade de Educação Profissional, já são tradicionalmente ofertados por escolas de aprendizagem profissional ligadas ao Serviço Nacional de Aprendizagem Comercial (SENAC) e Serviço Nacional de Aprendizagem Industrial (SENAI), que compóem a rede conhecida como Sistema S. Essas escolas visam atender às demandas de qualificação de cada setor e oferece um amplo portfólio de cursos, para os quais qualquer pessoa, com ou sem deficiência pode concorrer às vagas, desde que preencha os requisitos para cada curso. Para atender à demanda por qualificação gerada a partir da Lei de Cotas e ampliar a oferta de qualificação, instituiçóes filantrópicas sem fins lucrativos (Organizaçóes Não-Governamentais - ONGs) especializadas no atendimento exclusivo de pessoas com deficiência também passaram a ofertar tais cursos.

Mas para trabalhar com esse público adulto, com pouca ou nenhuma escolaridade, níveis de limitações impostas pela deficiência bastante diversificada, algumas questôes são suscitadas: Que adaptações curriculares estão sendo feitas pelas instituições de ensino que ofertam Educação Profissional para atender as necessidades educacionais das pessoas com deficiência que buscam qualificação? Existem diferenças no trabalho desenvolvido pelas escolas especializadas (que atendem exclusivamente pessoas com deficiência) e naquele desenvolvido pelas escolas do Sistema S (SENAC e SENAI)?

Para alcançarmos o objetivo proposto, além desta introdução, este artigo apresentará as normatizaçóes e as discussóes sobre as quais se assentam a educação profissional brasileira, considerando sua interface com a Educação Especial. Em seguida, serão narrados os procedimentos metodológicos, incluindo a apresentação e a fundamentação da metodologia de investigação. $\mathrm{Na}$ sequência, podem ser encontrados os resultados e as discussóes inerentes a esta investigação. De natureza qualitativa, a técnica utilizada para o tratamento dos dados foi a análise de conteúdo e, para explicitar o enfoque dado à temática 
tratada em cada uma das categorias encontradas, utilizou-se trechos das falas dos entrevistados. Na última parte, encontram-se as consideraçóes finais deste trabalho.

\section{Educação Profissional e Educação Especial}

O direito à educação pertence ao rol dos direitos humanos fundamentais, necessário no processo de construção de uma sociedade igualitária, democrática e justa. Como direito inalienável de todos os seres humanos, ela deve ser ofertada a toda e qualquer pessoa. Por parecer algo tăo óbvio, ninguém poderia negar às pessoas com deficiência o direito à educação. No entanto, o direito de exercer esse direito sem discriminação ainda gera muitos debates e embates no que diz respeito ao lugar em que as pessoas com necessidades educacionais especiais deverâo estudar.

Por muito tempo, as pessoas com deficiência permaneceram segregadas de ambientes educacionais por não serem consideradas sequer educáveis. Segundo Mendes (2006), a partir dos movimentos sociais pelos direitos humanos na década de 1960, houve maior sensibilização e conscientização por parte da sociedade a respeito dos prejuízos da segregaçáo e da marginalizaçáo de indivíduos que fazem parte de grupos com status de minoritário. Foi nesse contexto que a proposta de integraçáo escolar passou a fazer parte de açóes políticas, além da constatação de que as pessoas com deficiência poderiam aprender, e passou a ser discutido "o que", "para que" e "onde" elas poderiam aprender.

Essa política de integração durou mais de trinta anos no Brasil, o que contribuiu para fortalecer a exclusão de crianças indesejadas nas escolas públicas comuns (BUENO, 1993). Embora a Constituição brasileira (BRASIL, 1988) e a Lei de Diretrizes e Bases da Educaçáo Nacional (BRASIL, 1996) assegurem, há mais de vinte anos, a inclusão de alunos com deficiência nas classes comuns, ainda é muito recente a presença deles na rede regular de ensino.

Para viabilizar a ampliaçáo do acesso e a qualidade do processo educacional desses alunos, foi lançada a Política Nacional de Educação Especial na Perspectiva da Educação Inclusiva (BRASIL, 2008), de modo a atender ao princípio constitucional da igualdade de condiçóes de acesso e permanência na escola, e a continuidade de estudos nos níveis mais elevados de ensino. De acordo com este objetivo, a educação especial é definida como 
uma modalidade transversal a todos os níveis, etapas e modalidades, que atua de forma complementar ou suplementar ao ensino regular, disponibilizando serviços e recursos para as atividades de atendimento educacional especializado e a promoção da acessibilidade nos ambientes onde são desenvolvidos os processos educacionais.

No alinhamento com políticas internacionais que prezam pela equalização de oportunidades para as pessoas com deficiência, através do Decreto no 6.949 (BRASIL, 2009), que promulga a Convenção Internacional sobre os Direitos das Pessoas com Deficiência e seu Protocolo Facultativo, assinados em Nova York em 2007, o governo assume o compromisso com a Educação (artigo 24) e o Trabalho e Emprego (artigo 27) de pessoas com deficiência, proporcionando a elas o acesso ao sistema educacional inclusivo em todos os níveis, bem como o aprendizado ao longo de toda a vida e o acesso efetivo a programas de orientação técnica e profissional e a serviços de colocaçáo no trabalho e de treinamento profissional e continuado, entre outras açóes.

Essas políticas de promoção da inclusão na educação e no mercado de trabalho tem gerado bons resultados. O Censo Escolar 2012 já aponta para um grande aumento do número de pessoas com deficiência nas escolas, em todos os níveis. O Boletim de Indicadores do Mercado de Trabalho (BRASIL, 2011), também revela que em todos os meses do segundo quadrimestre do ano de 2011 houve elevação do número de pessoas com deficiência empregadas. Considerando que no Brasil há 45,6 milhóes de pessoas com deficiência, quase $1 / 4$ da população $(23,9 \%)$, nota-se que muito ainda há para se fazer no que diz respeito à promoção da igualdade de oportunidades.

Ao cruzar os dados dos Censos relativos à educação e trabalho, observa-se que o número de alunos com deficiência no ensino médio é cerca de $8,7 \%$ do número de alunos do ensino fundamental nas escolas regulares. Considerando as escolas exclusivas, de classes especiais, esse número é menor que $1 \%$. A Educação Profissional é a modalidade de ensino que recebe o menor número de alunos, sendo 1659 alunos em classes regulares e 737 nas classes especiais no ano de 2012. Isto mostra que ainda é precária a linearidade da escolarização dessas pessoas, o que se reflete diretamente nos rendimentos obtidos pelos trabalhadores com deficiência. Cerca de $46,4 \%$ dos que estão empregados ganham até um salário mínimo (IBGE, 2010), o que confirma os argumentos dos empregadores de que entre as dificuldades de contratação dessas pessoas está a sua baixa escolaridade. 
Para lidar com essa realidade de pessoas com deficiência, que na sua maioria tiveram percursos educacionais diferenciados, e ao mesmo tempo à vista da reserva de vagas criadas exclusivamente para elas em virtude da Lei de Cotas, tem se proliferado a oferta de cursos na modalidade Educaçáo Profissional em escolas de aprendizagem profissional que tradicionalmente ofertam cursos de preparação para o exercício profissional nos setores da indústria e do comércio (SENAI e SENAC, respectivamente) assim como nas instituições assistenciais que atendem este público. Segundo previsto no Decreto no 3.298 (BRASIL, 1999), a condiçáo imposta pelas instituiçôes educacionais para a matrícula de pessoas com deficiência em cursos profissionais de nível básico é a sua capacidade de aproveitamento e não o seu nível de escolaridade.

Mas para pessoas jovens e adultas que não traçaram sua vida escolar com base na linearidade exigida na educação básica, a relação entre educação e mundo do trabalho ocorre de forma muito mais imediata e contraditória (FRIGOTTO; CIAVATTA; RAMOS, 2005). Segundo Frigotto, Ciavatta e Ramos (2005), para essas pessoas, que geralmente retornam à escola ou a um curso de qualificação motivadas pelas dificuldades enfrentadas no mundo do trabalho, não é possível traçar linearmente uma etapa de formação básica voltada para a compreensão geral da vida social seguida de outra etapa que proporciona a instrumentalização para o exercício profissional. A formação profissional é um meio pelo qual o trabalhador adquire o conhecimento com o sentido de força produtiva, traduzindo-se em técnicas e procedimentos, conceitos científicos e tecnológicos básicos.

Como modalidade de ensino que perpassa todos os níveis, etapas e modalidades, a Educação Especial tem açôes voltadas também para a Educação Profissional. Para ampliar as oportunidades de escolarização, formação para o ingresso no mundo do trabalho e efetiva participação social, esta modalidade de ensino prevê o atendimento educacional especializado, a disponibilidade de recursos e serviços para o processo de ensino e aprendizagem em turmas comuns do ensino regular (BRASIL, 2008).

$\mathrm{O}$ atendimento educacional especializado é propiciado com o trabalho de profissionais com conhecimentos em Língua Brasileira de Sinais, Sistema Braille, do Soroban, da orientação e mobilidade, das atividades de vida autônoma, da comunicação alternativa, dos programas de enriquecimento curricular, adequação e produção de materiais didáticos e pedagógicos, utilização de recursos ópticos e não ópticos, tecnologia assistiva e outros (BRASIL, 2008). 
Atividades, recursos de acessibilidade e pedagógicos devem estar organizados institucional e continuamente, de forma complementar à formação dos estudantes com deficiência.

Isso requer que a proposta pedagógica curricular da escola contemple as adaptaçóes que garantem as condiçôes de acessibilidade e aprendizagem de todos os alunos. Essas transformaçôes são chamadas de adaptações curriculares: "O que o aluno deve aprender, como e quando aprender, que formas de organização de ensino são mais eficientes para o processo de aprendizagem, como e quando avaliar o aluno" (BRASIL, 1998, p .33) são os critérios a serem utilizados para fundamentar essas adaptaçóes.

Seguindo orientação dos Parâmetros Curriculares Nacionais (BRASIL, 1998), as medidas adaptativas podem se distinguir em adaptaçóes de acessibilidade curricular e adaptaçôes pedagógicas ou curriculares propriamente ditas. As adaptaçôes de acessibilidade consistem na criação de condições físicas, ambientais e materiais na unidade escolar, adequando o ambiente físico da mesma; a aquisição do mobiliário necessário e dos equipamentos e recursos materiais específicos. Também está incluída a capacitação continuada dos professores e demais profissionais da Educação. As adaptações de acessibilidade ao currículo dizem respeito às ações empreendidas pela escola para eliminação de barreiras arquitetônicas, materiais e de comunicação, garantindo que o aluno especial possa frequentar a escola com autonomia, participando das atividades acadêmicas e extracurriculares propostas para os demais.

As adaptaçôes curriculares propriamente ditas são as que permitem a eliminação ou a introdução de objetivos específicos, complementares e/ou alternativos e de conteúdos, como forma de favorecer o desenvolvimento e a aprendizagem dos alunos com necessidades educacionais específicas. São modificaçóes realizadas no planejamento, nos objetivos da escola, nos conteúdos e de avaliação, no currículo como um todo ou em aspectos dele.

Na definição de Sacristán (2000), currículo é um meio pelo qual a escola se organiza e propóe seus caminhos e a orientação para a prática. No entanto, $o$ autor observa que não é apenas a proposição de uma forma de pensar a escola e seus objetivos de maneira burocrática e mecânica. É preciso considerar todo o contexto em que isso ocorre e as consequências na prática pedagógica e na formação do educando. Para ele, as funçóes que o currículo cumpre, como forma de expressão do projeto de cultura e socialização, são realizadas através de seus conteúdos, de seu formato e também das práticas que cria em torno de si. 
Portanto, um currículo pensado para uma escola inclusiva deve ser dinâmico e flexível, pois é a partir das necessidades especiais apresentadas pelos alunos que os recursos para a aprendizagem, diferentes dos usuais, serão requeridos. Para Ciavatta e Rummert (2010), a elaboraçáo de uma proposta curricular não pode ser definida independentemente dos sujeitos envolvidos no processo, nem das dimensóes histórica e política em que é elaborada. Isso exige do projeto pedagógico uma adaptação progressiva do currículo regular, e não um novo currículo, para que não haja prejuízo do conteúdo a ser ministrado.

$\mathrm{Na}$ educação profissional de pessoas com deficiência, os princípios epistemológicos orientadores da construção social do currículo precisam destacar a relação entre a totalidade e a particularidade, entre aquilo que faz parte do conteúdo geral, necessário para a formação do "cidadão produtivo" e aquilo que é particular, inerente à necessidade de cada pessoa para apreender conhecimentos científicos e tecnológicos exigidos no mundo do trabalho.Para integrar política educacional e política de geração de emprego e renda para esse público que conjuga pouca ou nenhuma escolaridade básica, necessidades educacionais especiais de aprendizagem e necessidade de qualificaçáo profissional, é preciso considerar a organização de um projeto de educação organizado em etapas sequenciais, progressivas e flexíveis e estruturadas de forma a abarcar vários níveis de conhecimentos.

É com esse intuito de conhecer, na prática, as faces e interfaces no universo dessa articulação entre educação profissional e educação especial de jovens e adultos com deficiência que este artigo foi pensado.

\section{Procedimentos Metodológicos}

Este artigo situa-se numa abordagem qualitativa dos fenômenos sociais, em que a construção do conhecimento ocorre pela compreensão e a interpretação do fenômeno, utilizando como fonte de informaçóes os significados que os participantes da pesquisa atribuem à realidade de suas vivências. A pesquisa é do tipo exploratória, em que o investigador, voltado para a descoberta e não para a previsão de hipóteses, formulou questôes que lhe permitiram definir o foco da investigação.

O objetivo deste trabalho foi alcançado graças à participação de representantes das instituiçóes educacionais selecionadas para a pesquisa e que estavam à frente do planejamento e organização de programas relacionados à 
empregabilidade de pessoas com deficiência. Numa primeira fase, Morse (1994) afirma que os participantes escolhidos deverão ser "peritos experienciais" no fenômeno - aqueles que possuem sobre ele um conhecimento particular e aprofundado e que podem maximizar a informação que se pretende recolher.

Os dados, recolhidos em forma de palavras dos entrevistados e não em números, não poderão ser extrapolados para outras situaçóes que não a estudada, visto que a amostragem não foi realizada seguindo o critério de representatividade. Portanto, este trabalho náo oferece representatividade estatística.

O trabalho de campo ocorreu no segundo semestre de 2011 e a escolha de São Paulo (SP) se deu em razão desta cidade registrar maior número de pessoas com deficiência formalmente empregadas, segundo dados da RAIS (BRASIL, 2010).

A Secretaria Municipal da Pessoa com Deficiência e Mobilidade Reduzida (SMPED) da cidade de São Paulo foi escolhida como ponto de partida para buscar melhor direcionamento para a exploração deste campo. Para a delimitaçấo das instituiçôes que participariam, foram selecionadas as Organizaçôes Não Governamentais (ONGs) que oferecem educação profissional, e as escolas de aprendizagem do Sistema S (SENAC e SENAI), que há muito tempo no Brasil trabalham com educação profissional.

Cinco ONGs foram selecionadas seguindo a orientação da SMPED. As que contribuíram com este trabalho foram: Fundação Dorina Nowill, Associação Brasileira de Assistência ao Deficiente Visual (LARAMARA), Associação de Deficientes Visuais e Amigos (ADEVA), Lar e Escola São Francisco e Associação de Valorização da Pessoa com Deficiência (AVAPE).

Um representante de cada escola foi entrevistado, sendo que os do Sistema $S$ foram identificados com as siglas RIS 01 , RIS 02 , as quais servem para designar "Representante do Sistema S 01 e 02". Os representantes das ONGs (RIONG) foram identificados como RIONG 01, RIONG 02, RIONG 03, RIONG 04 e RIONG 05.

Entrevistas semiestruturadas foram utilizadas como instrumento de coleta de dados. As mesmas foram gravadas, com a prévia autorizaçáo dos entrevistados/as e posteriormente transcritas. $\mathrm{O}$ roteiro foi previamente estabelecido com base nos objetivos específicos traçados, observando o que prevê a legislação do Ministério da Educação que rege a educação profissional e 
sua interface com a Educação Especial. Esse roteiro serviu como guia para cada entrevista, oferecendo um baixo nível de direção na condução da conversa, de modo que os/as entrevistados/as pudessem retratar livremente suas concepçóes, práticas e vivências relacionadas à sua experiência profissional.

Os dados coletados foram tratados por meio da Análise de Conteúdo (BARDIN, 1979), de forma essencialmente temática, feita com base nos vários temas previamente determinados pelo roteiro de entrevista. O tratamento das informaçōes deu-se com a organização de uma Matriz de Agrupamento Temático, tomando como base para a definição dos temas os objetivos específicos propostos neste artigo. As temáticas para a caracterização das adaptações na educação profissional ofertada para as pessoas com deficiência seguiu a categorização proposta nos Parâmetros Curriculares Nacionais (BRASIL, 1998), que distingue as medidas adaptativas em adaptaçóes de acesso ao currículo e medidas adaptativas nos elementos curriculares.

Neste artigo, limitou-se a análise dos cursos de Educação Profissional apenas no nível de formação inicial e continuada, que inclui todos os níveis de escolaridade e podem ser ofertados segundo itinerários formativos (BRASIL, 2004).

Seguindo orientação de Vergara (2007), optou-se por uma grade fechada, na qual se definem antecipadamente as categorias relacionadas ao objetivo de pesquisa. Com essa matriz, as questóes da entrevista foram elaboradas e organizadas em categorias.

A seleçáo de trechos de discursos foi necessária para evidenciar o que foi dito pelos entrevistados, procurando respeitar, tanto quanto possível, o sentido das narrativas integrais. Segundo Bogdan e Biklen (1994), um bom trabalho qualitativo é documentado em boas descriçôes provenientes dos dados para ilustrar e substanciar as asserçóes feitas.

\section{Medidas adaptativas para o currículo de Pessoas com Deficiência na Educação Profissional}

A inclusão de alunos com necessidades educacionais especiais acompanha um movimento mundial pela educação que prioriza o direito de todos aprenderem juntos nas classes regulares de ensino. A Declaração de Salamanca (UNESCO, 1994), ao dispor das regras padrôes sobre equalizaçấo 
de oportunidades para pessoas com deficiência, proclama que as escolas regulares com orientaçáo inclusiva são os meios mais eficazes de combater atitudes discriminatórias, ajudando na construção de uma sociedade inclusiva e alcançando a educação para todos.

Para operacionalizar o currículo escolar que atende às necessidades de aprendizagem de todas as pessoas, com deficiência ou não, a proposta pedagógica que define a prática escolar precisa planejar medidas e desenvolver estratégias para eliminar barreiras que dificultam ou mesmo impedem o acesso do aluno ao currículo escolar. Para oferecer respostas educacionais adequadas às dificuldades de aprendizagem dos alunos, adaptaçóes no currículo regular devem ser previstas, não para criar um novo currículo, mas para torná-lo dinâmico, passível de ampliação para atender a todos os educandos (BRASIL, 1998).

Adaptaçóes curriculares constituem, segundo os Parâmetros Curriculares Nacionais (BRASIL, 1998), possibilidades educacionais de atuar frente às dificuldades de aprendizagem dos alunos. Este estudo orientou-se exatamente pela busca dessas possibilidades criadas para pessoas com deficiência jovens e adultas que buscam cursos na modalidade de Educação Profissional. Antes mesmo de iniciar a apresentação e discussão dos resultados encontrados, considera-se necessário apresentar, brevemente, um panorama do modo que as instituições organizam a oferta dos cursos nesta modalidade.

Nas escolas do SENAC e SENAI a oferta de cursos de educaçáo profissional é voltada para toda a comunidade e o candidato com deficiência concorre igualmente com outras pessoas, sem deficiência, pelas vagas em cada curso. No ato da inscrição ele precisa preencher os requisitos de seleção, tal como a escolaridade mínima exigida para o curso, assim como qualquer outro candidato, e declarar o tipo de recurso que precisará para fazer a prova de seleção. Sendo aprovado na seleçáo, ele ira frequentar o curso em classes regulares. Classes especiais são formadas apenas quando alguma empresa ligada ao setor do comércio ou da indústria precisa contratar um determinado número de pessoas com deficiência para cumprir a cota. A empresa contratante seleciona os candidatos ao curso e os enviam à escola de aprendizagem profissional para que se submetam ao curso indicado pela empresa.

As ONGs, por sua vez, trabalham com classes especiais. Das cinco instituiçóes pesquisadas, quatro atendem exclusivamente pessoas com a deficiência que as vincula à instituição. Se for uma instituição que atende pessoas com deficiência visual, por exemplo, as turmas serão formadas apenas 
por pessoas com este tipo de deficiência. $\mathrm{Na}$ única instituição que atende a vários tipos de deficiência, classes especiais são formadas por alunos com diferentes tipos de deficiência.

Esse atendimento especializado das ONGs apenas para pessoas com deficiência decorre, em grande parte, do histórico da instituição de trabalhar especificamente com esse público, como entidade de apoio. A pessoa com deficiência necessita de serviços especializados e por isso procura essas organizações em busca de reabilitação, apoio social, cuidados para sua saúde, entre outros serviços. Como, geralmente, elas estão organizadas para atender um tipo de deficiência específica, acabam oferecendo cada vez mais serviços para suprir outras necessidades que surgem.

A história da oferta da educação profissional em algumas ONGs é uma prova desse incremento de novas atividades para atendimento de outras demandas. Segundo relatos dos entrevistados, algumas instituiçóes começaram oferecendo serviços de saúde para pessoas com deficiência física, como consultas médicas e oferta de próteses. Com a Lei 8.213 (BRASIL, 1991), que cobra das empresas a contratação de Pessoas com deficiência, houve uma procura por candidatos nessas instituiçóes, o que motivou a começar um trabalho de intermediação candidato/vaga. No entanto, o resultado não era satisfatório, visto que ambas as partes, trabalhador com deficiência e empresa, não estavam satisfeitos. A empresa alegava falta de qualificação do trabalhador com deficiência, e este, por sua vez, alegava que não lhe era oferecida uma atividade motivadora na empresa. Diante desses fatos, as ONGs resolveram preparar as pessoas com deficiência antes desta intermediação, mantendo os outros serviços.

Há, portanto, uma migração das pessoas dentro da própria instituição, em busca de serviços diferenciados. Após receber a prestação do serviço de saúde, por exemplo, elas passam a buscar outros serviços prestados pela própria ONG, que inclui a oferta de cursos de qualificação profissional. Dessa forma, ela usufrui dos serviços daquela instituição por maior tempo, o que denota o quanto as pessoas com deficiência carecem de serviços básicos. Devido à maior proximidade com este público, que permanece mais tempo na instituiçâo, as ONGs se tornam grandes conhecedoras das questôes que envolvem a pessoa com deficiência e as condições para a sua inclusão profissional. Com base nisso, segue a análise dos resultados encontrados no que tange às medidas adaptativas de acesso ao currículo e adaptaçóes nos elementos curriculares. 


\section{Adaptaçóes para acesso ao currículo}

Cada pessoa tem um conjunto de saberes que lhe é bastante particular, resultado de um histórico de oportunidades de aprendizagens anteriores e das características pessoais. Por isso há que se considerar a singularidade de cada sujeito em sala de aula para adotar medidas adaptativas que favoreçam a aprendizagem e promovam a inclusão de todos.

Em todas as escolas pesquisadas foram encontradas modificaçóes tanto nos elementos físicos quanto materiais de ensino, bem como nos recursos utilizados pelo professor para trabalhar junto aos alunos com deficiência. Notadamente, há uma grande diferenciação quanto à abrangência com que essas adaptaçôes curriculares são feitas, quando se compara Sistema S (SENAC e SENAI) com as ONGs.

Nas escolas do SENAI e do SENAC, alguns recursos já são institucionalizados, ou seja, já existem previamente na escola e são disponibilizados quando uma pessoa com deficiência visual ou auditiva necessita. Esses recursos pedagógicos são o intérprete de Libras, quando há pessoas com deficiência auditiva, e o material ampliado ou em Braille, para pessoas com deficiência visual, softwares específicos, conforme explicitado nos trechos abaixo:

RIS 01: [...] é necessário verificar o quê que ele precisa. Se é um deficiente auditivo, por exemplo, eu vou precisar de um intérprete de libras nos cursos. [...]. Se é um deficiente visual, que ele precisa de um material em Braille, a gente vai providenciar um material em Braille ou um material ampliado. Então, depende da deficiência.

RIS 02: [...] a gente tem alguns recursos já institucionalizados. Por exemplo, no centro universitário, eu tenho um espaço Braille. A gente disponibiliza todos os recursos de vocalizadores para todas as unidades. Então, esses recursos, eles já estão presentes. E de adaptações [...] elas acontecem muito caso a caso, porque a grande presença é a da deficiência física. Tem as adaptaçôes de recursos, por exemplo. Tem lá uma apostila, então, é preciso que ela seja feita em letra ampliada ou ela seja impressa em Braille. Nos cursos de TI [Tecnologia da Informação], provavelmente vai ter uma adaptação de software. Então, isso depende muito. 
Então, assim quando o aluno entra, quando o aluno com deficiência chega, o coordenador vai olhar para o plano de curso né, vai olhar para as características do aluno e uma vez que ele identifique que vá precisar de determinados recursos ele já solicita né [...]. A gente fala: ah, será que os banheiros estão bem sinalizados, né? Então, assim você tem uma preocupaçấo que é antes, que já é da estrutura, mas no momento do atendimento, isso se intensifica mais né [...] a partir do momento que esse aluno chega ai que vai acionar todos os recursos pra o a atendimento.

Como se pode notar, as alteraçôes feitas nas escolas do Sistema $S$ são relacionadas às modificaçóes na estrutura física do ambiente, tais como adaptaçôes em banheiros, e sistemas de comunicaçâo (Braille, uso de softwares, intérpretes de Libra, tipos escritos ampliados). Alguns recursos, já institucionalizados, fazem parte da estrutura que as escolas têm adotado no seu planejamento para atender as pessoas com deficiência.

No entanto, fica bem evidente que em uma das escolas do sistema $S$ a oferta de recursos é bem focada no tipo de deficiência que o aluno apresenta e não na limitação dele. Pode ser que nem todos os alunos com deficiência visual, por exemplo, saibam ler através de Braille, o que tornaria sua disponibilização para o aluno completamente inútil, assim como nem toda pessoa com deficiência auditiva conhece a língua de sinais.

Cada pessoa com deficiência possui limitaçóes que lhes são muito particulares, pois dependem muito da sua história de vida, da autonomia, do grau de comprometimento da limitação, do seu jeito de aprender. Tratar esses desiguais como se todos fossem iguais, uniformes pelo tipo de deficiência apresentada, apenas contribui para limitar a inclusão. Não é a existência do recurso que vai garantir uma escola inclusiva, mas sim o atendimento da necessidade requerida pelo aluno, em sua particularidade, tendo deficiência ou não.

Para atender de forma inclusiva é preciso disponibilizar os materiais relacionados ao conteúdo a ser trabalhado no curso em diferentes formatos e de maneira integral. Nem todos os cegos sabem Braille, o que exigiria a oferta de outros recursos, em outros formatos, para oportunizar ao aluno o acesso à informação. A dificuldade de acesso aos conteúdos, a quantidade e a qualidade deles quando transcritos, também podem comprometer o princípio da igualdade 
de acesso curricular. Em relação às pessoas com deficiência visual, por exemplo, Coimbra (2002) aponta que nem sempre o material didático transcrito em Braille é disponibilizado em tempo hábil para os alunos, o que compromete o desenvolvimento de suas atividades em compasso com os demais alunos videntes. Quando a escola adota uma postura reativa à chegada do aluno com deficiência, fazendo dessa chegada o ponto de organização da estrutura que será ofertada a ele, é possível que haja comprometimento da sua aprendizagem em razão do atraso na oferta dos recursos.

As ONGs pesquisadas, especializadas no atendimento de pessoas com um tipo específico de deficiência e já com acúmulo de experiências no que tange aos diferentes níveis de limitaçóes das pessoas, oferecem mais adaptaçóes para que as pessoas com deficiência tenham acesso ao currículo. Tais adaptaçóes são planejadas e disponibilizadas de acordo com as necessidades da pessoa e não de acordo com o tipo de deficiência.

Os recursos utilizados nas classes especiais da Educação Profissional contemplam o uso de tecnologias assistivas, tais como leitores de telas, recursos para adequação postural de cadeirantes, o uso de bengalas e lupas eletrônicas. Para apoiar o uso do computador, há os dispositivos apontadores alternativos, que substituem o uso do mouse, teclados alternativos, ampliadores de tela, leitores de tela com sintetizadores de voz, impressoras Braille, entre outros. Os trechos a seguir explicitam melhor esta utilização das tecnologias assistivas pelas ONGs.

RIONG 01: [...] as pessoas com deficiência visual, elas precisam de softwares específicos pra essa população, que facilitam a entrada dessa população no mercado.

RIONG 03: [...] essas salas de informática [...] têm toda a tecnologia assistiva pra qualquer pessoa com qualquer tipo de deficiência poder fazer os nossos cursos de informática.

O termo tecnologia assistiva é bastante utilizado para identificar esses recursos e serviços que contribuem para proporcionar ou ampliar as habilidades funcionais de pessoas com deficiência. Radabaugh (1993) compara o uso da tecnologia para pessoas com e sem deficiência. Segundo o autor, para as pessoas sem deficiência, a tecnologia torna as coisas mais fáceis e, para as pessoas com deficiência, a tecnologia torna as coisas possíveis. Esses recursos e serviços são 
utilizados na educação como forma de promover a aprendizagem das Pessoas com deficiência (BRASIL, 2008).

$\mathrm{O}$ uso desses recursos faz com que o próprio aluno tenha condiçóes de explorar os conteúdos de seu interesse. Além de eliminar possíveis dificuldades relativas à exploração do material pedagógico em sala de aula, esses alunos também ficam preparados para acessarem os conteúdos relativos ao seu trabalho, quando tais recursos são disponibilizados pelas empresas. E ainda que isto não aconteça, ele tem conhecimento do que é necessário para que lhe seja dada uma condição de trabalho.

Materiais em Braille, com uma descrição detalhada dos conteúdos por parte dos docentes que são previamente preparados para trabalhar com esse público, são alguns dos recursos utilizados pelas ONGs, conforme descrito a seguir:

RIONG 01: [...] a gente transforma essa apostila em Braille, transforma essa apostila em tipos ampliados para pessoas com baixa visão e, quando é uma apostila, por exemplo, que tem imagens, a gente busca fazer o quê? Busca fazer a descrição dessas imagens. E pros professores foi uma coisa completamente nova porque a gente sempre orienta e apoia nesse sentido, de que quando eles vão fornecer alguma aula, falar sobre algum perfume, tal, que eles, então, usem muito da descrição ou usem de outros recursos que promovam a aprendizagem dessas pessoas [...]. Quando a gente vai transmitir essa informação, então, a gente vai transmitir através de vivências, através de todo um trabalho vivencial, pra que esses alunos, então, não fiquem só com essa informação. [...] Uma das professoras montou todo um, um, maquetes mesmo, das cavernas, do homem pré-histórico, do cheiro do corpo humano que era o cheiro que vigorava na... quer dizer, até pra começar a entender esse universo. Então, assim, todo o currículo, ele foi pensado mirando esses alunos

As ONGs também disponibilizam os conteúdos de aulas no formato de $\mathrm{CD}$ para os alunos que náo puderam comparecer à aula ou mesmo para aqueles que manifestam o desejo de ouvir novamente a aula do professor em casa. Dessa forma, o aluno tem mais um formato alternativo para acessar as aulas do curso. 
RIONG 05: [...] quem quer registrar a aula com o gravador, traz o gravador, quem usa a máquina, quem... Tudo bem. A pessoa pode, ou ela vai escrever, usa ampliado ou náo. Nós fazemos as apostilas e textos utilizados na aula em braille ampliado Para os outros cursos, a gente tem dado o CD. Porque têm os outros cursos de informática. A massagem, a gente fez uma gravação, ou em CD ou mesmo em áudio, da apostila. Porque alguns que fazem massagem e que estão dentro dos critérios e que têm a idade, têm a escolaridade, mas que podem ter tido a perda visual, mas que não quiseram fazer braille etc., então, a gente tem a apostila gravada. Então, nem sempre é o braille ou o ampliado que vai resolver.

Além dessas adaptaçóes, a adequação do mobiliário para cadeirantes e outras pessoas com deficiência física, por exemplo, é planejada de modo que o aluno tenha uma postura que lhe ofereça conforto durante a aula. Esses ajustes deveriam transcender o trabalho de reabilitação e aparecer nas salas de aula e nos ambientes de trabalho, porque é condição básica para que o aluno não sinta desconforto durante a aprendizagem escolar.

RIONG 02: [...] cada aluno tem a sua necessidade especifica. Então eu posso ter, por exemplo, duas pessoas com lesão medular cadeirantes, um que vai precisar de adaptação é diferente do segundo. Então a gente tem que ter uma atenção individualizada. Então é difícil no sentido de que a gente tem que providenciar adaptaçóes pra cada um $e$ às vezes isso exige investimento financeiro e às vezes exige flexibilidade da equipe né. Um precisa do apoio do pé, outro precisa de uma mesa mais alta e a gente precisa sambar até arrumar uma mesa que caiba cadeira e tal... [...] um pode precisar de uma mesa mais alta, outra mais baixa, então é um atendimento personalizado. Isto é uma dificuldade, mas é também uma condiçâo inerente a isso, porque se você quer capacitar pessoa com deficiência, você vai ter que solucionar isso. Mas é um detalhe que se você fosse oferecer um curso sem essa preocupação, você não precisaria.

Atender a essas particularidades das necessidades individualizadas é um desafio para a gestáo da educaçáo profissional, que exige o envolvimento de 
todos na percepção dos "arranjos" que precisarão ser feitos no cotidiano da prática escolar. Por isso propor o acesso inclusivo, por si só, não é suficiente. Professores, gestores e demais profissionais envolvidos com a educação inclusiva precisam ter formação voltada para a diversidade, pois a realidade do cotidiano escolar requer conhecimento e prática voltada para a diversidade, nem sempre possível de ser prevista.

Se existem formas de solucionar de maneira satisfatória a acessibilidade das pessoas com deficiência aos conteúdos escolares, à interação com a sociedade, estas devem ser conhecidas pelos docentes, especializados ou não, em educaçáo especial, antes que digam "não" a um aluno pelo mero desconhecimento sobre o que pode ser a ele oferecido.

Como se pode notar, as escolas do SENAC e SENAI tem se preparado para ofertar serviços educacionais na perspectiva da educaçáo inclusiva, institucionalizando o uso de alguns recursos para colocá-los em uso quando necessários. Como a efetivaçáo desse movimento pela educação inclusiva ainda é recente, especialmente quando se fala de escolas para adultos, será necessário maior envolvimento da gestão para compreender as necessidades dos educandos e responder mais efetivamente a elas, também numa perspectiva individual.

A opção pelos recursos que melhor atendam às necessidades dos alunos deve partir de uma análise detalhada, individual, com cada aluno. As necessidades deles são bastante específicas não só em virtude do nível de comprometimento que a deficiência impóe, mas também decorrem da história de vida de cada um.

Segundo Almeida et al. (2011), quanto melhor a infraestrutura disponibilizada pela escola aos alunos com deficiência, melhor é o rendimento deles. Quando esta infraestrutura não é adequada, a evasão e o abandono da escola são muito mais frequentes. Algumas adaptações são facilmente previstas, como aquelas que incluem modificaçóes na estrutura do ambiente físico da escola para permitir a acessibilidade. Para outras adaptaçóes, é preciso conhecer a pessoa e suas necessidades mais específicas, de modo que barreiras para a aprendizagem sejam removidas. Muitas vezes, é ao longo da própria ação pedagógica que essas adaptaçôes irão se efetivando.

\section{Adaptaçôes nos elementos curriculares}

Um projeto pedagógico cuja concepção básica é a "educação para todos" deve atender as diferenças individuais dos alunos operacionalizando estratégias 
de adaptaçóes nos elementos componentes do currículo. Essas medidas adaptativas focalizam alteraçóes realizadas na metodologia e didática e nos conteúdos curriculares e processo avaliativo.

Segundo os Parâmetros Curriculares Nacionais (BRASIL, 1998), são exemplos dessas medidas adaptativas: adotar métodos e técnicas de ensino e aprendizagem específicas para o aluno; utilizar instrumentos de avaliação distintos da classe, quando necessário e cuidando para que isso não altere objetivos e conteúdo da avaliação; oferecer apoio físico, visual, verbal e outros ao aluno impedido em suas capacidades para permitir a ele a realização das atividades escolares; introduzir atividades escolares complementares para o aluno alcançar os objetivos comuns aos demais colegas; suprimir atividades, objetivos e conteúdos curriculares que não restrinjam a participação do aluno em razão de sua deficiência, substituindo-os por objetivos e conteúdos acessíveis; estender por um período mais longo o curso e, consequentemente, as disciplinas, para que o aluno possa alcançar os objetivos comuns ao grupo; introduzir ou eliminar conteúdos, objetivos e critérios de avaliação definidos para o grupo de referência do aluno em razão de suas limitações pessoais, atentando para não causar prejuízo à sua escolarização e promoção acadêmica.

No Sistema $S$ os entrevistados afirmaram que como o currículo é construído para atender a todas as pessoas, não é necessário fazer alteraçôes. Quando há formulação de um novo plano de curso para atender uma demanda específica de pessoas com deficiência para uma empresa, o currículo não é pensado com foco naquele público-alvo, mas sim em todas as pessoas a quem aquele curso poderia servir. Como mencionado por outra pessoa entrevistada do Sistema $S$, dificilmente os planos de curso requerem adaptaçóes maiores quando há uma pessoa com deficiência em sala de aula. Pois como há baixo número de pessoas com deficiência nos cursos regulares do sistema $S$, sendo maioria pessoas com deficiência física (LIMA, 2012), o currículo é construído pensando numa maioria sem deficiência.

RIS 01: Recentemente, a gente formatou um curso pra uma empresa que não existia na nossa carteira de cursos, mas que a empresa estava solicitando. Era pra um grupo de pessoas com deficiência e foi formatado um plano de curso novo pra atender essa solicitação dessa empresa [...], mas não é um curso especifico pra pessoas com deficiência. Aquela turma era de pessoas com deficiência, mas fez-se um plano de curso de certa forma pra qualquer aluno. 
RIS 02: [...] dificilmente, os planos de curso, eles requerem uma adaptação muito maior.

É possível que os entrevistados estejam considerando como currículo apenas o conteúdo programado para o curso. Mas, conforme Sacristán (2000), além de conteúdo, um currículo também incorpora práticas desenvolvidas por meio de múltiplos processos. A sua concepção reflete as intenções educativas quanto ao planejamento e ao desenvolvimento do processo ensinoaprendizagem, englobando as atividades programadas e desenvolvidas, as atividades administrativas e pedagógicas, que afetam tanto a prática do professor, considerado como elemento de primeira ordem na concretizaçáo desse processo, quanto à aprendizagem dos alunos.

Se considerarmos apenas o conteúdo, realmente o currículo deveria ser o mesmo para todos os alunos, sob o risco subestimar a capacidade de aprendizagem de alguns e prejudicar sua formação, comprometendo ainda mais a competitividade de pessoas com deficiência na disputa por vagas no mercado de trabalho, mesmo dentro das cotas. Mas quando são propostos acréscimos ou eliminação de conteúdos em um currículo inclusivo não é para comprometer o conhecimento que o indivíduo deve receber, sob o risco de negar a ele o direito à igualdade na aprendizagem, mas sim para facilitar o seu acesso a este conteúdo levando em consideração que as pessoas com deficiência são desiguais em virtude de diferenças físicas, sensoriais, intelectuais e de história de vida.

Um currículo engessado, construído para atender a todos, como se todos fossem exatamente iguais, que não leva em consideração a diversidade dos que participam desse processo, compromete o desenvolvimento real de habilidades e aptidôes dos indivíduos com deficiência, cujo ponto de partida na aquisição de conhecimentos para a vida social e produtiva é diferente das demais pessoas. Segundo Fuller e Clark (1994), uma das falhas frequentes das propostas políticas de inclusão escolar é a tendência de tentar padronizar o processo, encontrar remédios universais para desenvolver práticas pedagógicas únicas sem atender às diversas configuraçóes culturais.

As ONGs, por sua vez, constroem um currículo com base no público-alvo, no perfil de pessoas a quem o curso pretende alcançar. Além do conteúdo que envolve a habilitaçấo para um trabalho, os cursos incluem conteúdos que visam o desenvolvimento de habilidades do indivíduo para a vida em sociedade, visando 
o exercício da cidadania. A formação pessoal e profissional é contemplada, o que faz com que esses currículos sejam ampliados.

As adaptaçóes no conteúdo do currículo são propostas com intuito de complementar o trabalho de formação profissional. Essas temáticas funcionam como oficinas e tem em vista promover a reflexáo dos alunos por meio da discussão de temas ligados às dificuldades da vida com deficiência, direitos e deveres do cidadáo, preconceito, talento, habilidades, empreendedorismo, ética, entre outras.

RIONG 01: [...] as oficinas de empregabilidade têm como objetivo conversar sobre questóes voltadas para a área profissional. [...]. A gente aborda a questão do preconceito, a questão de direitos e deveres, explicamos sobre questôes de porque que existe a Lei de Cotas, falamos sobre talento, habilidades, recursos de tecnologia assistiva, sobre ética no ambiente de trabalho, sobre relacionamento e convivência no ambiente de trabalho, sobre empreendedorismo.

RIONG 03: [...] módulos que são especificos do curso que ele tá fazendo, mas a gente também trabalha os módulos na parte básica. A gente forma ele como cidadão. A gente fala de ética, a gente fala de cidadania, a gente fala da autoestima, a gente fala de português, a gente fala de matemática, ele tem aula de etiqueta profissional.

Além disso, uma análise da história de vida dos alunos é levada em consideração para promover adaptaçóes no currículo que promovam sua inclusão no mercado de trabalho e, antes de tudo, na sociedade. Muitos dos jovens e adultos com deficiência que procuram as ONGs para obter qualificação são levados por algum familiar, pois nunca saíram de casa sem auxílio de alguém ou não tem confiança para se locomoverem sozinhos. Tendo em vista essa emancipação, as ONGs incluem no currículo orientação à mobilidade, que é uma das condiçōes para a pessoa ir ao trabalho e se locomover no ambiente da organizaçấo, sem depender da assistência de outrem.

RIONG 04: É feita uma entrevista, é feita uma triagem com a pessoa. A pessoa passa por uma entrevista onde é detectada a necessidade dela, o que que ela precisa. Tem gente 
que chega aqui sem saber absolutamente nada. [...] chegam casos de pessoas que perderam a visão, então você precisa encaminhar para o Braille, pra mobilidade. A mobilidade é o ensino do uso da bengala. Que são duas coisas básicas para a pessoa ir para o mercado de trabalho: que tem o Braille né, que é um sistema de escrita e leitura da pessoa cega e a mobilidade, que vai proporcionar a independência. É inconcebivel você perceber, você admitir uma pessoa numa empresa sem que ela saiba se locomover sozinha. Isso é inconcebivel. Então você tem que dar condiçóes minimas pra pessoa ir pro mercado de trabalho. E isso a gente faz aqui.

Algumas ONGs trabalham conteúdos específicos do ensino básico na educação profissional, como uma forma de reparar parte da dificuldade que os alunos com deficiência enfrentam ao ler, escrever, calcular, raciocinar mais rapidamente, como colocado por um entrevistado:

RIONG 02: Ai do ponto de vista pedagógico, o que que a gente decidiu oferecer para os alunos né. Primeiro, a gente teve que responder a uma demanda natural do mercado que, assim, a maior parte das vagas oferecidas pelas empresas são nas áreas administrativas. Então a gente achou por bem desenvolver um curso de auxiliar administrativo. [...] Então, pra esse curso, a gente tem uma carga horária grande de um módulo que se chama módulo de desenvolvimento comportamental. Esse módulo tem uma carga horária de cerca de 90 horas e é a parte do curso que a gente poderia chamar de capacitação, porque é quando a gente fala de posturas profissionais, sobre o ambiente corporativo, sobre a atitude profissional, sobre identificar a sua vocação né. Então acoplado ao desenvolvimento comportamental a gente tem um módulo de orientação profissional, que a gente aplica testes, faz dinâmicas de grupo, conduzido por um psicólogo da equipe, pra que cada um no final do módulo tenha um relatório feito em conjunto com a psicóloga, mas que tem suas maiores aptidóes, seus interesses e tal. Passando ai pra parte da qualificação tem um módulo de noçôes básicas em administração. Então eles têm acesso à rotina administrativa de uma grande corporação, à linguagem $e$ às estratégias comuns de uma grande corporação né. E 
ai pra complementar essa qualificação a gente dá módulos de português e matemática porque mesmo na maioria dos nossos cursos tenha o critério de que tenham concluido o ensino médio ou que estejam terminando o ensino médio, a gente vê pela produção desses alunos que o conhecimento das operaçôes básicas de matemática e de português são muito precários. Daí não tem a ver com a população de pessoas com deficiência, mas acho que tem a ver com a qualidade do ensino no nosso país né. Muitos deles vêm da educação formal pública né... Então vem com falhas graves na área de português e matemática. Então a gente achou por bem dar uma repassada no conteúdo de português e matemática visto no ensino médio, mas já trazendo uma noção da empresa. Eu vou trabalhar a lingua portuguesa dentro de uma aplicação viável dentro da empresa. Então a gente vai trabalhar como escrever um ofício, como escrever um e-mail, como corrigir a ortografia e a gramática, mas sempre num cenário que se aproxime da empresa.

$\mathrm{Na}$ proposta curricular da educação profissional voltada para pessoas com deficiência e desenvolvida nas ONGs, há uma finalidade compensatória em relação à falta de educação básica. Nos diferentes itinerários formativos, há pessoas com pouca ou nenhuma escolaridade e pouca autonomia para se deslocar sem auxílio de um familiar até pessoas com alguma escolaridade e que já estavam no mercado de trabalho, mas querem adquirir outras qualificaçôes para melhorar seu posicionamento na empresa ou melhores empregos.

É a demanda do mercado de trabalho que orienta o planejamento do curso a ser ofertado, evidenciando a relaçáo entre o que se aprende na escola e o que é funcional à produção. Além disso, a proposta pedagógica que conjuga capacitação, orientação profissional e qualificação, permite a construção de itinerários formativos que vão além da formação técnica para uma ocupaçâo específica.

A capacitação é focada no desenvolvimento comportamental, na formação de atitudes que são requeridas nas atividades de trabalho. A orientação é focada no próprio indivíduo, que recebe assistência para descobrir suas aptidóes, habilidades e assim se adequar melhor às possibilidades e condiçóes de trabalho. A qualificação, última etapa desse itinerário formativo, é voltada para a aquisição de conhecimentos que seráo operacionalizados para o exercício profissional. 
Nesse itinerário formativo proposto, os saberes para o exercício da cidadania são gradativamente incorporados e confrontados com os saberes exigidos no mundo do trabalho.

RIONG 03: [...] não é só visar à inclusão dela no mercado, mas ela ser protagonista, ela ter o papel dela como cidadão, ela saber exercer esse papel, né... [...] é mostrar pra ele qual é o potencial dele [...], é ele saber se comportar numa entrevista, ele saber se colocar na sociedade, ele saber quais sáo as vestimentas adequadas para ele ir numa entrevista pra ele poder executar o papel dele na tarefa dele, no posto de trabalho, como montar um curriculo, né... A gente trabalha de tudo, desde a parte de saúde, politica, higiene, apresentaçáo pessoal, ética, cidadania.

RIONG 05: [...] a gente se rendeu realmente à questão do mundo do trabalho, que a gente realmente trabalha muito com isso aqui, não dá pra fugir né. Mas com grande foco na questão da autonomia, que também é objetivo de qualquer proposta educacional que é visar à autonomia e a independência da pessoa e a cidadania é também objetivo geral da nossa educação [...] temos um outro módulo que é Etica, Cidadania e Mundo do Trabalho [...] a gente trabalha com questöes de competências para o trabalho, mas não o trabalho x ou y. Mas a gente inicia com Ética, Moral, Direitos Humanos, Direitos das Pessoas com Deficiência. E ai entra um pouco dessa coisa do mundo do trabalho, de globalização, de mercado.

Pelo exposto, percebe-se uma grande diferença no trabalho desenvolvido por instituiçôes de apoio à pessoa com deficiência e naquele desenvolvido pelo Sistema S. Os conhecimentos adquiridos ao longo dessa experiência educacional de ONGs visam ajudar o jovem e adulto com deficiência a constituir saberes para a vida cotidiana, importantes para sua inserção no mercado de trabalho, de forma que esse sujeito de aprendizagem possa se reconhecer enquanto cidadão e trabalhador.

Sob a tese de ofertar uma escola para todos e pensar num currículo para o curso independentemente de quem ele irá atender, as escolas do SENAC e SENAI podem assumir o risco de excluir na inclusão dos ambientes escolares 
pessoas com deficiência, mesmo quando oferecem a "capacitação customizada". Como identificado no trabalho de Lima (2012), o "todos" que esses sistemas atendem é, na verdade, a maioria sem deficiência, visto que, conforme resultados encontrados no referido trabalho e ilustrado na fala abaixo, as pessoas com deficiência que procuram a rede $S$ para se qualificar tem um perfil diferenciado no que diz respeito à autonomia e escolaridade.

\begin{abstract}
RIS 02: Já é um aluno que tem uma certa autonomia [...] que já tem um processo assim de... de metas, de objetivos, já muito definidos, né. Não é um aluno que, que ele apresente uma caracteristica assistencialista, que tenha essa coisa de que ele venha a procura de um atendimento aonde ele vai ser assistido. Não é essa característica. É um aluno que já tem seu nivel de independência. Muitas vezes ele já trabalha, muitas vezes ele vem de um processo de estudo já consolidado sabe, já tá estudando.
\end{abstract}

\title{
Considerações finais
}

O estudo da educação profissional voltada para pessoas com deficiência na cidade de Sáo Paulo apontou que todas as instituiçóes que ofertam a educaçáo profissional fazem adaptaçóes curriculares para atender ao aluno que busca por qualificação profissional.

Nas escolas do Sistema $S$, o objetivo é a preparação do aluno para as ocupaçôes do mercado de trabalho com base na qualificação técnica, no aprender a fazer. Nas ONGs, como parte de um processo de desenvolvimento do indivíduo, as aprendizagens relacionadas ao saber conhecer, ser e conviver também são acrescentas aos currículos dos cursos. Isso mostra que a educação profissional proposta pelo SENAI e SENAC preparam para uma ocupação de uma função, enquanto a ofertada pela ONG está mais vinculada à preparaçâo do indivíduo para o exercício autônomo de sua cidadania.

As adaptaçóes curriculares realizadas no sistema $S$ acompanham o movimento pela inclusão de alunos com necessidades educacionais especiais na escola regular. Medidas adaptativas para o acesso ao currículo são disponibilizadas de acordo com a deficiência apresentada pelo aluno e não na pessoa com suas necessidades específicas. As escolas disponibilizam intérpretes 
de libras, softwares e Braille para viabilizar a comunicação nas aulas, além de fazer adaptaçôes ligadas à infraestrutura, tal como adaptações em banheiros e elevadores. Mesmo quando há classes especiais, não foram relatadas adaptaçôes nos elementos curriculares para adequá-los às necessidades educacionais dos alunos, visto que o currículo permanece voltado para o atendimento de "todos", assim sendo, a maioria sem deficiência.

Sabe-se que a existência e disponibilidade desses recursos não são suficientes para garantir a aprendizagem dos alunos, visto que o perfil do grupo de pessoas que atualmente busca por qualificação vem há muito tempo acumulando as consequências de negaçáo dos seus direitos, inclusive à educação regular, pública, de qualidade e que atendesse às suas necessidades educacionais. Tais recursos não suprem as necessidades de aprendizagem dos alunos que não tiveram educação básica, que não tiveram experiências de exercício da cidadania ao longo da vida.

Ainda que o aluno possa integrar uma escola regular com alguns recursos, há que se perguntar se por fazer parte de um grupo minoritário, eles estão prontamente disponibilizados ou a escola ainda precisará de certo tempo para providenciá-los? Os materiais utilizados em sala nem sempre são previstos com antecedência para que sejam providenciados em tempo hábil para os alunos com deficiência. Alunos cegos, por exemplo, que precisam de textos e livros em Braille, se ele souber Braille, terá que esperar quanto tempo por seu material? No Brasil, é fácil fazer um material em Braille em qualquer cidade?

Longe de duvidar dos benefícios da educação inclusiva, mas tomando a realidade do estudo como crítica, oferecer atendimento educacional especializado para pessoas com deficiência ainda faz parte do que minimamente pode ser ofertado a elas. Promover uma "equidade mínima" (FRIGOTTO, 2007) já é um avanço para quem sempre teve negado o direito à educação, em qualquer nível, mas não chega a ser suficiente para que pessoas com deficiência possam exercer seu direito ao trabalho conforme sua livre escolha.

As ONGs fazem muitas adaptaçóes curriculares, considerando as necessidades e os perfis individuais dos alunos. Com turmas menores e homogêneas, no que tange ao tipo de deficiência, elas utilizam sua expertise para adotar estratégias diferenciadas no ensino. $\mathrm{O}$ uso de recursos de tecnologia assistiva, adaptaçóes no mobiliário para atender às necessidades de acomodação do aluno, uso de mídias alternativas para que os alunos possam rever conteúdos em outros formatos, ensino do uso de bengala, Braille, língua de sinais, são 
alguns exemplos de medidas adaptativas adotadas por essas instituições para favorecer a acessibilidade do aluno ao currículo.

A oferta de educação profissional pelas escolas, sejam elas especiais ou regulares, é um desafio. Além do atendimento às necessidades educacionais de pessoas com deficiência requerer atenção individualizada, recursos e adaptações específicas, há também o fato de que essa modalidade de ensino ainda não se articula com outros níveis educacionais e, muitas vezes, nem mesmo é continuada, visto que alguns alunos nunca frequentaram a escola.

Essas características exigem a formulação de propostas pedagógicas comprometidas com a emancipação humana e não simplesmente com o ensino de conteúdos fragmentados, exclusivamente voltados para o conhecimento necessário ao trabalho produtivo. A educação profissional reduzida ao adestramento para o mercado (FRIGOTTO, 2007) e à preparação para o exercício de funçóes operacionais (CIAVATTA; RUMMERT, 2010), não permite que seres humanos possam produzir dignamente sua existência e nem contribuem para a redução da desigualdade. A estas pessoas sempre ficará destinado um lugar no mercado de trabalho que não lhe permite muitas escolhas, apenas um emprego precário, com baixo salário, como confirmam os dados do último Censo do IBGE comentados anteriormente.

Dada a polêmica sobre a extinção de classes especiais pela substituição de atendimento educacional especializado em todas as escolas regulares e tomando como base a realidade experienciadas por este estudo, supóe-se que, pelo perfil de pessoas adultas com deficiência, ainda seja necessária a convivência desses dois tipos de escolas. Pessoas com deficiência com alguma escolaridade e maior nível de autonomia buscam escolas do sistema $S$, com ampla oferta de cursos, para concorrer e estudar em igualdade de condiçóes com outras pessoas sem deficiência, enquanto aquelas com nenhuma ou pouca escolarização e baixo nível de autonomia, ainda precisam percorrer os itinerários formativos propostos no trabalho diferenciado das entidades filantrópicas para o seu desenvolvimento pessoal e profissional. Para Oliveira e Haddad (2001), esse papel desempenhado pelas ONGs é resultado da falta de comprometimento do setor público com a educação, em que elas são chamadas a colaborar na ação direta de serviços educacionais, em que o Estado se retira ou nem mesmo entra.

Trabalhar com esta temática impóe a necessidade de rever muitas questóes polêmicas que estão imbricadas na educação. Como essa realidade mostra-se bastante complexa, esse artigo não houve a pretensão de responder 
todas as questóes ainda em discussão no que concerne à educação profissional de pessoas com deficiência. Pretendeu-se apenas ajudar a esclarecer uma parte dessa realidade, com vistas a auxiliar nas discussóes inerentes à propostas educacionais verdadeiramente inclusivas para a formaçáo dessas pessoas para o mundo do trabalho.

\section{REFERÊNCIAS}

ALMEIDA, Luciana A. D. et al. Desempenho de alunos com deficiência na rede regular de ensino: impactos da infraestrutura de acessibilidade e da formação docente. Pesquisas e Práticas Psicossociais, São João Del-Rei, MG, v. 6, n. 1, p. 16-28, jan./jul. 2011.

BARDIN, Laurence. Análise de conteúdo. Lisboa: Ediçóes 70, 1979.

BOGDAN, Robert; BIKLEN, Sari. Investigação qualitativa em educação. Porto: Porto Editora, 1994.

BRASIL. Constituição da República Federativa do Brasil. Brasília, DF, 1988. 415 p.

Lei no 8.213, de 24 de julho de 1991. Dispóe sobre o plano de benefícios da Previdência Social, e dá outras providências. Diário Oficial da União, Brasília, DF, 25 jul. 1991. Disponível em: <http://www.planalto.gov. br/ccivil_03/leis/L8213cons.htm>. Acesso em: 10 out. 2011.

Lei no 9.394, de 20 de dezembro de 1996. Estabelece as diretrizes e bases da educação nacional. Diário Oficial da Uniāo, Brasília, DF, 23 dez. 1996. Disponível em: <http://www.planalto.gov.br/ccivil_03/leis/19394. htm>. Acesso em: 10 out. 2011.

Ministério da Educação. Secretaria de Educação Fundamental. Secretaria de Educação Especial. Parâmetros Curriculares Nacionais: adaptaçôes curriculares. Brasília: MEC, 1998.

. Decreto no 3.298, de 20 de dezembro de 1999. Regulamenta a lei 7853/89, dispóe sobre a política nacional para a integração da pessoa portadora de deficiência, consolida a norma de proteçáo, e dá outras providências. Diário Oficial da Uniāo, Brasília, DF, 21 dez. 1999. Disponível em: <http://www.planalto.gov.br/ccivil_03/decreto/d3298.ht>. Acesso em: 10 out. 2011. 
BRASIL. Decreto no 5.154, de 23 de julho de 2004. Regulamenta o $\$$ $2^{\circ}$ do art. 36 e os arts. 39 a 41 da Lei no 9.394 , de 20 de dezembro de 1996, que estabelece as diretrizes e bases da educação nacional, e dá outras providências. Diário Oficial da União, Brasília, DF, 23 jul. 2004.

Decreto no 6.949, de 25 de agosto de 2009. Promulga a Convençáo Internacional sobre os Direitos das Pessoas com Deficiência e seu Protocolo Facultativo, assinados em Nova York, em 30 de março de 2007. Diário Oficial da União, Brasília, DF, 28 ago. 2009. Disponível em: <http://www. planalto.gov.br/ccivil_03/_ato2007-2010/2009/decreto/d6949.htm>. Acesso em: 13 jan. 2013.

Ministério da Educação. Secretaria de Educação Especial. Política Nacional de Educação Especial na perspectiva da educação inclusiva. Inclusâo: Revista de Educação Especial, Brasília, DF, v. 4, n. 1, p. 7-17, jan./ jun. 2008.

. Ministério da Educação. Instituto Nacional de Estudos e Pesquisas Educacionais. Resultado do censo da educação básica 2009. Brasília, DF, 2009. Disponível em: <http://download.inep.gov.br/download/censo/2009/TEXTO_ DIVULGACAO_EDUCACENSO_20093.pdf>. Acesso em: 8 dez. 2011.

BRASIL. Instituto Nacional de Estudos e Pesquisas Educacionais Anísio Teixeira. Censo da Educação Básica: 2012: resumo técnico. Brasília, DF: INEP, 2013. Disponível em: <http://download.inep.gov.br/educacao_basica/ censo_escolar/resumos_tecnicos/resumo_tecnico_censo_educacao_ basica_2012.pdf >. Acesso em: 12 jan. 2013.

Relação Anual de Informaçôes Sociais: 2007/2008/2009. Brasília, DF, 2010. Disponível em: <http://www.rais.gov.br>. Acesso em: 10 out. 2011.

BRASIL. Ministério do Trabalho e Emprego. Boletim de indicadores do mercado de trabalho pessoas com deficiência no 05. Brasília, DF: Observatório do mercado de trabalho nacional do MTE, 2011. Disponível em: <http:// portal.mte.gov.br/data/files/8A7C816A3345B2BF01334675D7DF2930/ indicadores_boletim_01.pdf>. Acesso em: 10 jan. 2013.

BUENO, José Geraldo Silveira. Educação especial brasileira: integração/ segregação do aluno diferente. São Paulo: Editora da PUC/SP, 1993. 
CIAVATTA, Maria; RUMMERT, Sonia Maria. As implicaçóes políticas e pedagógicas do currículo na educação de jovens e adultos integrada à formação profissional. Educação \& Sociedade, Campinas, SP, v. 31, n. 111, p. 461-480, abr./jun. 2010.

COIMBRA, Ivâne Dantas. A inclusão do portador de deficiência visual na escola regular: alguns desafios. Revista da FAEEBA: educação e contemporaneidade, Salvador, v. 11, n. 17, p. 45-55, jan./jun. 2002.

FRIGOTTO, Gaudêncio. A relação da educação profissional e tecnológica com a universalização da educação básica. Educação \& Sociedade, Campinas, SP, v. 28, n. 100, p. 1129-1152, 2007.

FRIGOTTO, Gaudêncio; CIAVATTA, Maria. A formação do cidadão produtivo. Brasília, DF: INEP, 2006. Disponível em: <http://www. publicacoes.inep.gov.br/arquivos/\%7B2CE88044-7714-4383-9E1390FDC8D6517C\%7D_miolo_A\%20forma\%C3\%A7\%C3\%A3o\%20 do\%20cidad\%C3\%A3o\%20produtivo_4\%C2\%AA\%20vers\%C3\%A3o_ ULTIMO.pdf>. Acesso em: 10 jan. 2013.

FRIGOTTO, Gaudêncio; CIAVATTA, Maria; RAMOS, Marise. O trabalho como princípio educativo no projeto de educação integral de trabalhadores. Educação integral e sistema de reconhecimento e certificaçâo educacional e profissional. São Paulo: CUT, 2005. p. 19-62.

FULLER, Bruce; CLARKE, Prema. Raising school effects while ignoring culture? Local conditions and the influence of classroom tools, rules, and pedagogy. Review of educational research, Berkeley, v. 64, n. 1, p. 119-157, 1994.

IBGE. Instituto Brasileiro de Geografia e Estatística. Censo 2010: número de católicos cai e aumenta o de evangélicos, espíritas e sem religiáo. Brasília, DF, 2010. Disponível em: <http://censo2010.ibge.gov.br/noticias-censo?view=no ticia\&id=3\&idnoticia $=2170 \&$ busca $=1 \& \mathrm{t}=$ censo- 2010 -numero-catolicos-caiaumenta-evangelicos-espiritas-sem-religiao>. Acesso em: 10 jan. 2013.

LIMA, Michelle Pinto de. Educação profissional de pessoas com deficiência: um estudo na cidade de São Paulo. 2012. 189 p. Dissertação (Mestrado em Educação) - Universidade Federal de Lavras, Lavras, MG, 2012. 
MENDES, Enicéia Gonçalves. A radicalização do debate sobre inclusão escolar no Brasil. Revista Brasileira de Educação, Rio de janeiro, v. 11, n. 33, p. 387-405, set./dez. 2006.

MORSE, Janice. Designing funded qualitative research. In: DENZIN, Norman K.; LINCOLN, Yvonna S. (Ed.). The sage handbook of qualitative research. London: Sage, 1994. p. 220-235.

OLIVEIRA, Anna Cynthia; HADDAD, Sérgio. As organizaçôes da sociedade civil e as ONGs de educação. Cadernos de Pesquisa, São Paulo, v. 112, p. 61-83, mar. 2001.

RADABAUGH, Mary Pat. Study on the financing of assistive technology devices of services for individuals with disabilities: a report to the president and the congress of the United State. Chicago: National Council on Disability, 1993. Disponível em: <http://www.ccclivecaption.com>. Acesso em: 4 dez. 2011.

RIBEIRO, Marco Antônio; CARNEIRO, Ricardo. A inclusão indesejada: as empresas brasileiras face à lei de cotas para pessoas com deficiência no mercado de trabalho. Organizaçóes \& Sociedade, Salvador, v. 16, n. 50, p. 545-564, jul./set. 2009.

SACRISTÁN, J. Gimeno. O currículo: uma reflexão sobre a prática. 3. ed. Porto Alegre: Artmed, 2000.

TANAKA, Eliza D. O.; MANZINI, Eduardo José. O que os empregadores pensam sobre o trabalho da pessoa com deficiência? Revista Brasileira de Educação Especial, Brasília, v. 11, n. 3, p. 273-294, maio/ago. 2005.

UNESCO. Organização das Nações Unidas para a Educação, a Ciência e a Cultura. Declaraçấo de Salamanca e linha de ação sobre necessidades educativas especiais. Brasília: CORDE, 1994.

VERGARA, Sylvia Constant. Métodos de pesquisa em administração. 3. ed. São Paulo: Atlas, 2008. 


\section{Educación Profesional de las Personas con Discapacidad: adaptaciones para la accesibilidad}

\section{Resumen}

Este trabajo se realizó con el fin de conocer las adecuaciones curriculares realizadas en el ámbito de la Formación Profesional, que atiende a personas con discapacidad. Para el estudio, siete instituciones educativas que ofrecen este tipo de educación, siendo ellas: SENAC, SENAI y las organizaciones no gubernamentales (ONG) de servicios para personas con discapacidad. Se efectuaron entrevistas semi-estructuradas para la recolección de los datos a los representantes de las instituciones responsables de la planificación y la organización de los cursos. La naturaleza cualitativa del estudio permitió que el tratamiento de los datos sea realizado por medio del análisis de contenido, en especial por temáticas. Los resultados de la investigación muestran que las $\mathrm{ONG}$ están en relación con el sistema $S$ de la diversidad de las medidas de adaptación empleadas en la satisfacción de las necesidades educativas especiales de estas personas.

Palabras claves: Personas con discapacidad. Educación profesional. Adaptaciones curriculares.

\section{Professional Education for Pessoas com deficiência: adaptations for accessibility} Abstract

This paper was carried out in order to know the curricular adjustments made under the Professional Education, which serves people with disabilities. For the present study seven educational institutions that offer this type of education were selected. Data collection took place with the use of semi-structured interviews with representatives of those institutions that are in charge of the planning and organization of the courses. The qualitative nature of the study allowed the processing of data by content analysis, essentially thematically. The results from the investigation show that NGOs stand in relation to the $S$ system for the diversity of adaptive measures employed in meeting the special educational needs of these people.

Keywords: People with disabilities. Professional education. Curricular adaptations. 


\section{Michelle Pinto Lima}

E-mail:michelle17pi@gmail.com

\section{Mônica Carvalho Alves Cappelle}

E-mail:edmo@dae.ufla.br

Recebido em: 16/1/2013

Versão final recebida em: 20/7/2013

Aprovado em: 24/7/2013 